(C) 2017 IEEE. Personal use of this material is permitted. Permission from IEEE must be obtained for all other uses, in any current or future media, including reprinting/republishing this material for advertising or promotional purposes, creating new collective works, for resale or redistribution to servers or lists, or reuse of any copyrighted component of this work in other works. 


\title{
Polypyrrole RVC Biofuel Cells for Powering Medical Implants
}

\author{
Daniel N. Roxby, Student Member, S. R. Simon Ting, and Hung T. Nguyen, Senior Member, IEEE
}

\begin{abstract}
Batteries for implanted medical devices such as pacemakers typically require surgical replacement every 5 to 10 years causing stress to the patient and their families. A Biofuel cell uses two electrodes with enzymes embedded to convert sugar into electricity. To evaluate the power producing capabilities of biofuel cells to replace battery technology, polypyrrole electrodes were fabricated by compression with Glucose oxidase and Laccase. Vitreous carbon was added to increase the conductivity, whilst glutaraldehyde acted as a crosslinking molecule. A maximum open circuit potential of $558.7 \mathrm{mV}$, short circuit current of $1.09 \mathrm{~mA}$ and maximum power of $0.127 \mathrm{~mW}$ was obtained from the fuel cells. This was able to turn on a medical thermometer through a TI BQ25504 energy harvesting circuit, hence showing the powering potential for biomedical devices.
\end{abstract}

\section{INTRODUCTION}

The most recent global survey of cardiac pacing showed that over 1 million pacemakers were implanted in 2009, with 738000 of these were new pacemaker patients, whilst 265000 were replacements of old pacemakers [1]. These are staggering numbers, and represent one part of the ever growing global biomedical devices market. A major cause of the pacemaker surgical replacement occurring roughly every 5 to 10 years is to replace the battery. There is expected to be further issues with more devices coming to market that require increasing amounts of power.

Efforts to convert latent energy to electrical energy for implanted medical devices are an ongoing field of research. These include mechanical energy by piezoelectric, electrostatic and magnetic induction generators as well as heat energy with thermopiles [2]. Alternatively there is inductive charging from outside to inside the body [3].

One particular field of interest has been in biological fuel cells which can convert glucose into electricity. These involve either bacteria or enzymes to break down glucose and extract electrons and do not require additional patient effort or battery charging. Roxby et al has shown that numerous microbial fuel cells would be required to obtain the power requirements for implanted medical devices [4-6]. By contrast, enzymatic biological fuel cells (BFCs) can be much smaller and do not require bacteria as their catalyst [7].

Biological fuel cells have anode and cathode electrodes. The anode electrode will often contain either glucose oxidase (GOx) or glucose dehydrogenase to catalyze the breakdown of glucose to gluconolactone and the extraction of electrons. The electrons travel through the circuit to the cathode electrode

Daniel N. Roxby, S. R. Simon Ting and Hung T. Nguyen are with the Key Centre for Health Technologies, Faculty of Engineering and Information Technology, University of Technology, Sydney, Broadway NSW 2007, Australia. which usually contains either laccase (LAC) or Bilirubin which can transfer electrons to dioxygen and result in water.

Previous studies by Zebda et al $[8,9]$ have demonstrated compressed multiwalled carbon nanotube based electrodes giving high power output. In this study, we use porous functionalizable polypyrrole with enzyme immobilization, blended with reticulated vitreous carbon (RVC) for increased conductivity. The increased conductivity lead to a maximum open circuit voltage of $558.7 \mathrm{mV}$, a maximum short circuit current of $1.09 \mathrm{~mA}$ and a maximum power of $0.127 \mathrm{~mW}$.

\section{EXPERIMENTAL METHOD}

\section{A. Chemicals}

Glucose oxidase (GOx) from Aspergillus niger, Laccase (LAC) from Trametes versicolor, glutaraldehyde, Polypyrrole (Ppy, conductivity 10-50 S/cm) and Physiological Buffer Solution (PBS) tablets were purchased from Sigma Aldrich. Reticulated Vitreous Carbon was purchased from Goodfellow, whilst the glucose was purchased from Ajax Chemicals.

\section{B. Electrode Fabrication and BFC Setup}

Ppy (100 mg) and GOx (100 mg) or Laccase (100 mg) were mixed in plastic weigh boats, and then compressed into coin like electrodes by a force of 8000 tonnes in a hydraulic press to make the anode or cathode electrodes respectively. Each electrode was approximately $1.31 \mathrm{~cm}$ in diameter by 0.5 $\mathrm{mm}$ thick. A photo of the electrodes can be seen in Fig. 1.

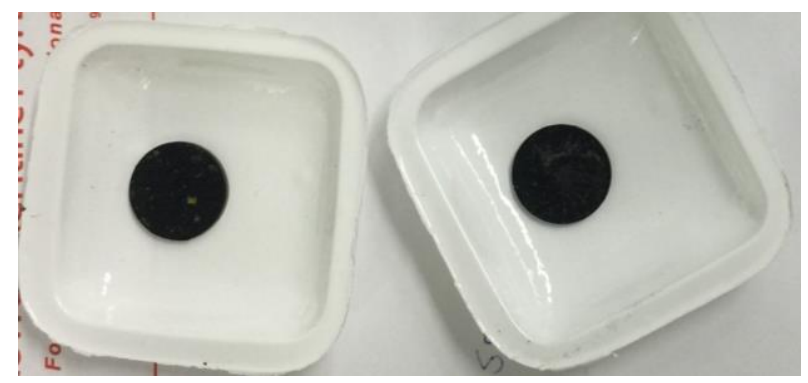

Figure 1 PHOTO OF THE COMPRESSED PPy ENZYME ELECTRODES. ON THE LEFT IF THE GOX ANODE AND ON THE RIGHT IS THE LAC CATHODE.

In order to increase the conductivity of the electrodes, the RVC (100 mg) was added to the above mixtures and compressed as above unless otherwise stated. The Ppy-RVC electrodes were approximately $1.31 \mathrm{~cm}$ in diameter and 1.1 mm thick.

Where enzyme immobilization was used, the aforementioned electrodes were compressed in the absence of enzymes. A method adapted from Jugovic et al was employed,

E-mail contacts: Daniel.Roxby@student.uts.edu.au, Simon.Ting@uts.edu.au, Hung.Nguyen@uts.edu.au. 
where the electrodes were coated with $70 \%$ glutaraldehyde solution and left to incubate for 1 hour [10]. GOx (50 mg) and Lac (50 mg) were dissolved in Physiological Buffer Solution (PBS, 2mL) in separate vials and the washed electrodes were added. The electrodes were left in their enzyme solutions for 20 hours and used as is. In this way, aldehyde groups on either side of glutaraldehyde were covalently bonded with amide linkages on both the polypyrrole and enzymes.

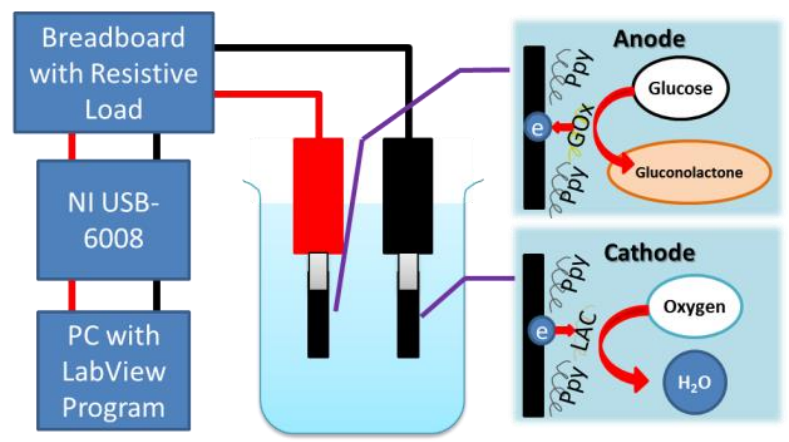

Figure 2. Biofuel Cell SchematiC - The ANODE CONTAins GOX Which BREAKS DOWN THE GLUCOSE, ALLOWING PPY TO CONDUCT THE ELECTRON TO THE CIRCUIT. THE ELECTRON THEN IS CONDUCTED TO THE LAC REACTION BY THE PPY CATHODE WHERE $\mathrm{H}_{2} \mathrm{O}$ IS CREATED WITH THE ELECTRON AND OXYGEN

To create the BFC, $100 \mathrm{mM}$ D-glucose was dissolved in 50 $\mathrm{mL}$ miliQ PBS solution. The electrodes were attached to the electrical circuit via alligator clips and then inserted into the solution at room temperature. An illustration of the BFC can be seen in Fig. 2.

\section{B. Measurement Setup}

Alligator clips with wires were connected to a NI USB6008 being controlled by a computer with a custom LabView program. The voltage was logged to a spreadsheet every 10 seconds for further analysis. The BFCs were left in opencircuit until the voltage stabilized, and loads of decreasing resistance were connected with their current calculated by Ohm's law $(\mathrm{V}=\mathrm{IR})$ and power $(\mathrm{P}=\mathrm{VI})$ for the polarization and power curves respectively. For each experiment, two fuel cells were run to ensure repeatability and in all voltage over time curves, the decreasing voltage at the end of each curve is due to the voltage and polarization curve tests. Resistance was measured in a 4-probe setup with an Agilent U3402A, without enzymes and conductivity calculated by $\rho=\mathrm{RA} / l$.

\section{RESULTS AND DISCUSSION}

\section{A. Compressed Ppy Enzyme Electrodes}

To test the potential of conductive polymers as compressed biofuel cell electrodes, polypyrrole was compressed into two electrodes with GOx and LAC, then bathed in a glucose-PBS solution and the resultant voltage was plotted as shown in Fig. 3 . The voltage initially increased sharply and gives a maximum of $175.12 \mathrm{mV}$ before gradually diminishing after a short time. The compressed Ppy electrodes had a conductivity of $2.59 \mathrm{mS} / \mathrm{cm}$.

When the voltage stabilized, the polarization and power curves were obtained as seen in Fig. 4. From these BFCs, a maximum of $1.11 \mu \mathrm{W}$ at $17.3 \mathrm{mV}$ and $64.07 \mu \mathrm{A}$ was obtained giving an internal resistance of $270 \Omega$. The short circuit current was $150 \mu \mathrm{A}$. During the operation of the BFC, enzymes visibly leached from the electrodes, possibly accounting for the low and short electrical output.

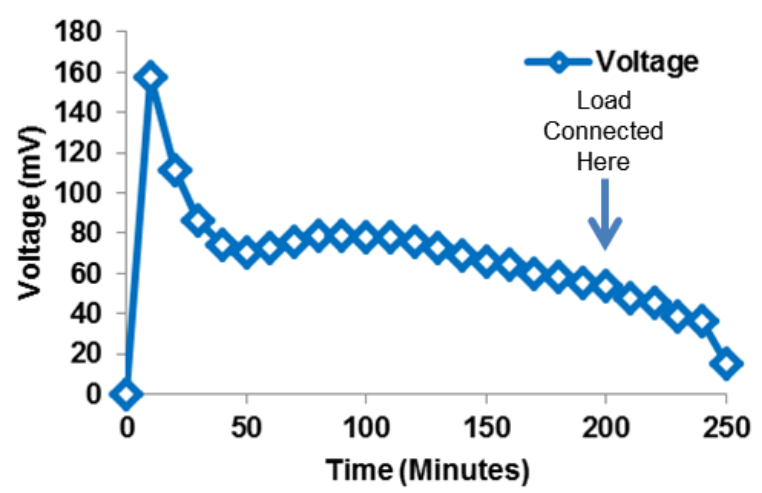

Figure 3 Voltage Over Time FOR COMPRESSEd PPy NON-IMMOBILIZED ENZYME ELECTRODES

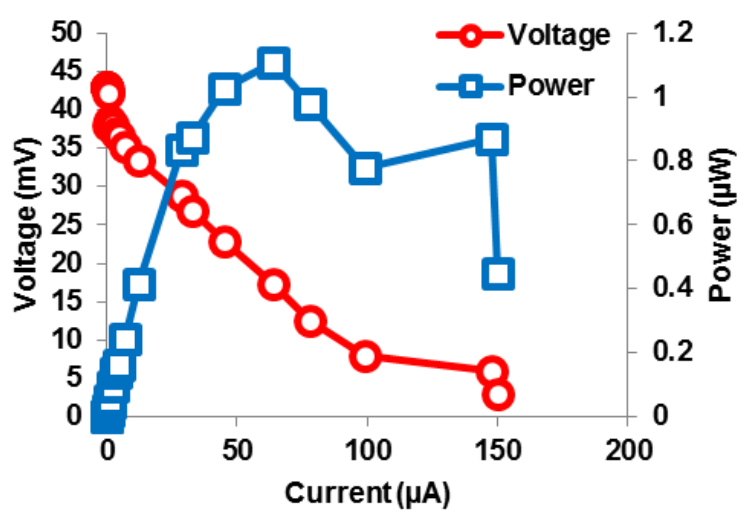

Figure 4 POLARIZATION AND POWER CURVES FOR COMPRESSED PPY NONIMMOBILIZED ENZYME ELECTRODES

\section{B. Compressed Ppy Electrodes with Immobilized Enzymes}

To enhance the ability of the electrodes to provide electricity over a longer time span, enzyme immobilization by way of glutaraldehyde, a dialdehyde-based crosslinking molecule, was used. This would provide a direct connection and anchoring between the enzyme and the conductive polymers. The voltage recorded over time is shown in Fig. 5 and remains longer, rising to a higher and constant voltage over 3 hours, with a maximum of $212.5 \mathrm{mV}$. Fig. 6 shows the polarization and power curves where with the enzymes immobilized, a peak power of $18.98 \mu \mathrm{W}$ at $137.8 \mathrm{mV}$ and $137.8 \mu \mathrm{A}$ was measured giving an internal resistance of 1000 $\Omega$. The short circuit current was $440 \mu \mathrm{A}$.

\section{Compressed Ppy-RVC Enzyme Electrodes}

The voltage of the compressed Ppy electrodes, whilst improved by enzyme immobilization, was still quite low. Studies with comparable methods use MWCNTs which are known to have conductivities of $10-100 \mathrm{MS} / \mathrm{cm}$ [11] and therefore could be a reason for the low electrical output. RVC is another common fuel cell electrode material and has conductivities of $10-20 \mathrm{kS} / \mathrm{cm}$ [12]. When crushed and compressed however RVC appears to be mechanically unstable and fell apart and therefore was mixed with Ppy to increase the stability of electrodes. The conductivity of the obtained Ppy was $14.84 \mathrm{mS} / \mathrm{cm}$. 
Fig. 7 shows the voltage over time, where a peak of 475.51 $\mathrm{mV}$ was measured which is more than double of the previous Ppy electrodes. Fig. 8 shows the polarization and power curves where a peak power of $127.45 \mu \mathrm{W}$ at $357 \mathrm{mV}$ and $357 \mu \mathrm{A}$ was measured giving an internal resistance of $1000 \Omega$. This power is more than 100 times greater than the original electrodes, indicating that electrical conductivity is a major contributing factor.

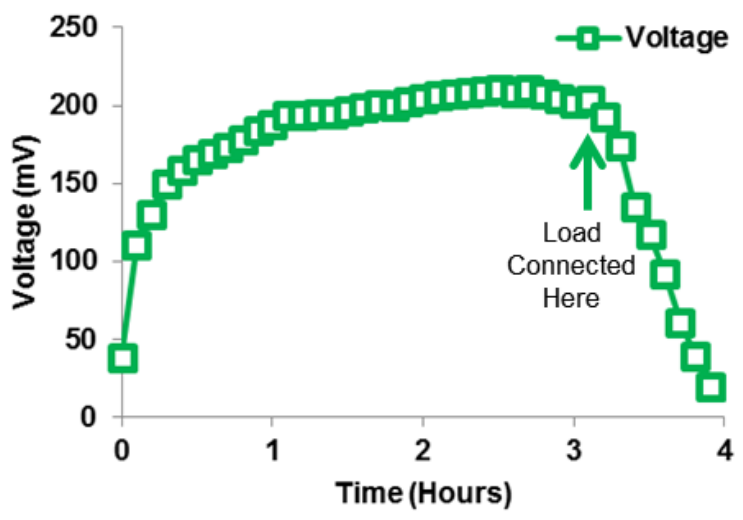

Figure 5 Voltage OVER Time For COMPRESSEd PPy IMMOBILIZED ENZYME ELECTRODES

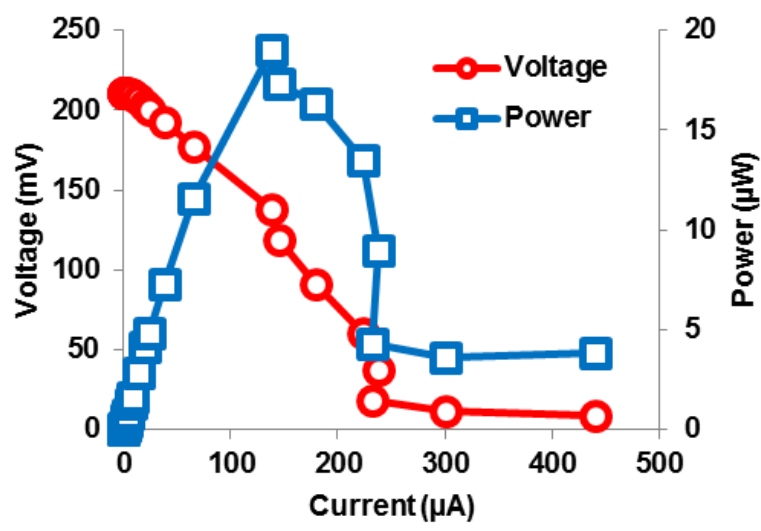

FiguRE 6 POLARIZATION AND POWER CURVES FOR COMPRESSED POLYPYRROLE ELECTRODES ENZYMES IMMOBILIZED

\section{Compressed Ppy-RVC Electrodes with Immobilized Enzymes}

A biofuel cell with compressed electrodes containing both RVC and Ppy with immobilized enzymes was tested. With the nature of RVC being that it crumbled easily, and that for enzyme immobilization, the electrodes were left in solution for 20 hours, the electrodes became fragile when attached to the alligator clips. To deal with this, $50 \mathrm{mg} \mathrm{RVC}$ was used and silicone was applied to one side of each of the electrodes for structural integrity. The conductivity of these electrodes was measured to be $6 \mathrm{mS} / \mathrm{cm}$.

Fig. 9 shows the voltage over time with a very fast response and a peak voltage of $558.7 \mathrm{mV}$. Fig. 10 shows the polarization and voltage curves where a peak power of 37.67 $\mu \mathrm{W}$ at a voltage of $194.1 \mathrm{mV}$ and a current of $194.1 \mu \mathrm{A}$ giving an internal resistance of $1000 \Omega$. The difference in current between the immobilized and non-immobilized PpyRVC electrodes could be explained by two possibilities. (1)
Electrodes with immobilized enzymes compared to directly compressed electrodes will inevitably contain less enzymes and (2) the surface area of the electrodes are reduced by the need for a silicone structure to prevent the electrode from falling apart.

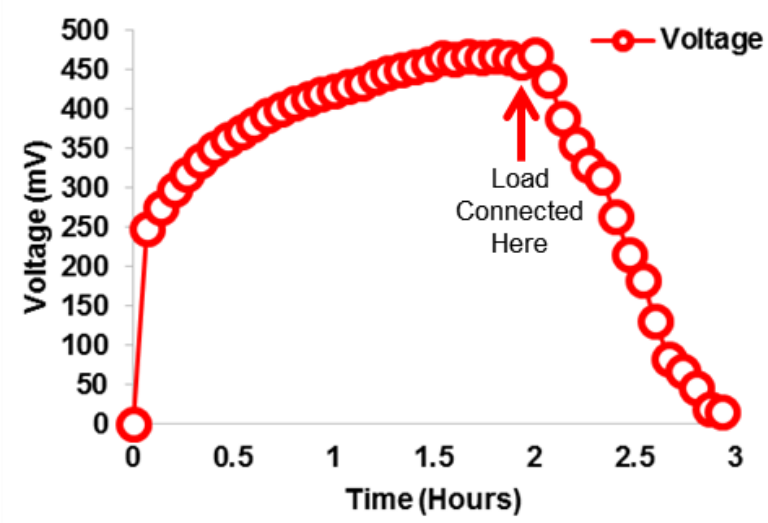

Figure 7 Voltage Over Time for Compressed Ppy-RVC Electrodes NON-IMMOBILIZED ENZYMES

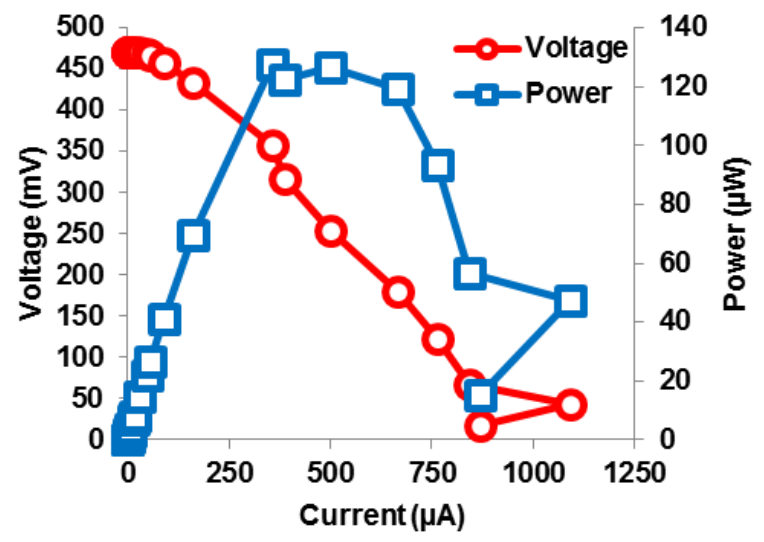

FIGURE 8 POLARIZATION AND POWER CURVES FOR COMPRESSED PPY-RVC ELECTRODES ENZYMES NON-IMMOBILIZED

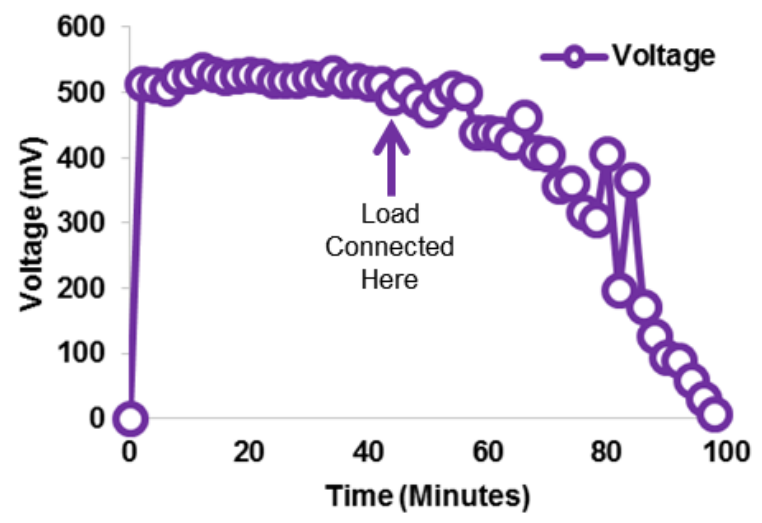

Figure 9 Voltage OVER Time FOR COMPRESSEd PPy-RVC ENZYME IMMOBILIZED ELECTRODES

\section{E. Connection to an Energy Harvesting Circuit}

Since the Ppy-RVC electrodes with non-immobilized enzymes provided the highest amount of power, these were connected to an energy harvesting circuit powering a V916CAUS Thermometer. The BFC was attached to the inputs of a 
TI BQ25504 and the output to a $470 \mu \mathrm{F}$ capacitor which a fully charged to $1.5 \mathrm{~V}$ was discharged through the thermometer. Fig. 11 shows a photo of the thermometer reading a temperature whilst being powered by the BFC. The thermometer has a specified power rating of $0.1 \mathrm{~mW}$ and was on for 14 seconds. $3 \mathrm{~V}$ is possible with at least 5 minutes charging time. For comparison, the Medtronic Micra M957651A001 operates with a $120 \mathrm{~mA}$.hr battery for 8 years with a current drain of $1.71 \mu \mathrm{A}$ at $1.5 \mathrm{~V}$ [13].

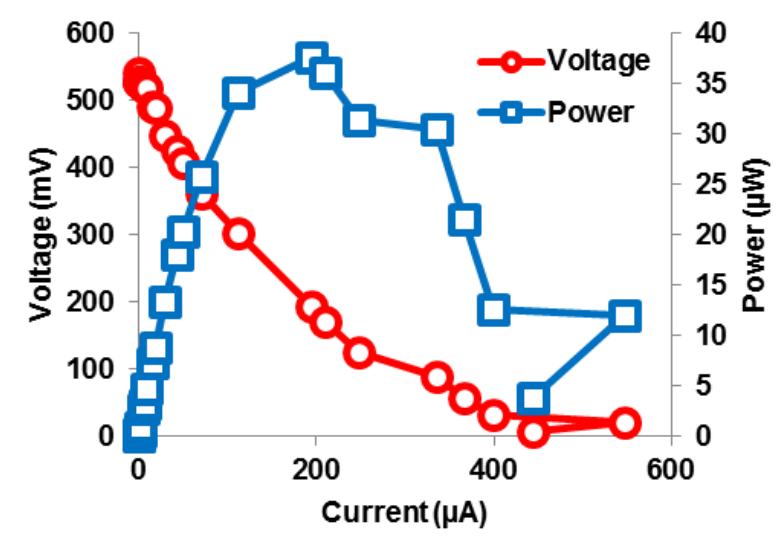

Figure 10 Polarization AND Voltage CuRVes For CoMPRESSED PPyRVC ENZYME ENZYME IMMOBILIZED ELECTRODES

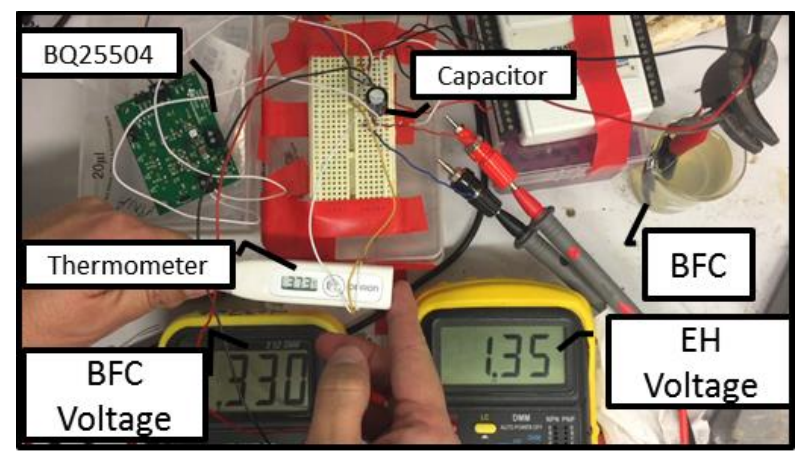

FIGURE 11 PHOTO OF A BODY THERMOMETER BEING POWERED BY A BQ25504 AND BFC

\section{CONCLUSION}

In this work, the ability of Ppy to be compressed and used with enzymes in a biofuel cell to generate power from glucose is shown. When Ppy was used by itself, significant enzyme leaching occurred, giving a peak voltage of $175.12 \mathrm{mV}$ and highlighting the need for enzyme immobilization. Ppy's functionality and porosity are advantageous however its conductivity is low. By mixing Ppy with $\mathrm{RVC}$, the conductivity increased, giving voltages of $475.51 \mathrm{mV}$ without enzyme immobilization and $558.7 \mathrm{mV}$ with immobilization. By doing this, it was found that to provide significant current, large amounts of enzyme are required, which enzyme immobilized on the surface alone of an electrode cannot provide. With the results that we obtained, in conjunction with an efficient step up converter, a body thermometer was powered.

Future work to further increase electrode conductivity by highly conductive materials such as titanium or silver would assist and would not have the mechanical issues when RVC was employed. Immobilizing enzymes throughout the electrode, rather than the surface alone could be experimented, increasing current generation and perhaps prevent voltage loss under load. Multi-point covalent bonding of enzymes may help with long term enzyme stability. Electrodes in electrical series or parallel for increased voltage or current respectively are also a possibility. Lastly, a small addition of catalase to the anode electrode can increase the voltage closer to ideal of approximately $900 \mathrm{mV}[8]$.

\section{ACKNOWLEDGMENT}

Many thanks go to the Centre for Health Technologies, for the funding and assistance through this project. The authors would also like to thank the National Health and Medical Research Council (NHMRC) Early Career fellowship (APP1054011) for funding support. Much support was also given by the Level 5 Chemical Technologies Laboratory of the University of Technology, Sydney.

\section{REFERENCES}

[1] H. G. Mond and A. Proclemer, "The 11th World Survey of Cardiac Pacing and Implantable Cardioverter-Defibrillators: Calendar Year 2009-A World Society of Arrhythmia's Project," Pacing and clinical electrophysiology, vol. 34, pp. 1013-1027, 2011.

[2] M. A. Hannan, S. Mutashar, S. A. Samad, and A. Hussain, "Energy harvesting for the implantable biomedical devices: issues and challenges," BioMedical Engineering OnLine, vol. 13, p. 79, 2014.

[3] S. Y. R. Hui, W. Zhong, and C. K. Lee, "A critical review of recent progress in mid-range wireless power transfer," IEEE Transactions on Power Electronics, vol. 29, pp. 4500-4511, 2014.

[4] D. N. Roxby, N. Tran, and H. T. Nguyen, "A simple microbial fuel cell model for improvement of biomedical device powering times," in Engineering in Medicine and Biology Society (EMBC), 2014 36th Annual International Conference of the IEEE, 2014, pp. 634-637.

[5] D. N. Roxby, N. Tran, P.-L. Yu, and H. T. Nguyen, "Experimenting with microbial fuel cells for powering implanted biomedical devices," in Engineering in Medicine and Biology Society (EMBC), 2015 37th Annual International Conference of the IEEE, 2015, pp. 2685-2688.

[6] D. N. Roxby, N. Tran, P.-L. Yu, and H. T. Nguyen, "Effect of growth solution, membrane size and array connection on microbial fuel cell power supply for medical devices," in Engineering in Medicine and Biology Society (EMBC), 2016 IEEE 38th Annual International Conference of the, 2016, pp. 1946-1949.

[7] S. Cosnier, A. Le Goff, and M. Holzinger, "Towards glucose biofuel cells implanted in human body for powering artificial organs: review," Electrochemistry Communications, vol. 38, pp. 19-23, 2014.

[8] A. Zebda, C. Gondran, A. Le Goff, M. Holzinger, P. Cinquin, and S. Cosnier, "Mediatorless high-power glucose biofuel cells based on compressed carbon nanotube-enzyme electrodes," Nature communications, vol. 2, p. 370, 2011.

[9] A. Zebda, S. Cosnier, J.-P. Alcaraz, M. Holzinger, A. Le Goff, C. Gondran, et al., "Single glucose biofuel cells implanted in rats power electronic devices," Scientific reports, vol. 3, p. 1516, 2013.

[10] B. Jugović, B. Grgur, M. Antov, Z. Knežević-Jugović, J. Stevanović, and M. Gvozdenović, "Polypyrrole-based enzyme electrode with immobilized glucose oxidase for electrochemical determination of glucose," Int. J. Electrochem. Sci, vol. 11, pp. 1152-1161, 2016.

[11] Y. Z. Jia Choi. (2011, 27 January). Single, Double, MultiWall Carbon Nanotube Properties \& Applications. Available: http://www.sigmaaldrich.com/technical-documents/articles/materialsscience/single-double-multi-walled-carbon-nanotubes.html

[12] AZoM. (2003, January 29). Supplier Data - Vitreous Carbon (Goodfellow). Available: http://www.azom.com/article.aspx?ArticleID=1838

[13] Medtronic, Medtronic Micra MC1VR01 Clinician Manual vol. Rev A. Minneapolis: Medtronic, 2016. 